\title{
Online collaborative learning: Opportunities for interprofessional education
}

\author{
Basil H. Aboul-Enein* \\ London School of Hygiene and Tropical Medicine, Department of Global Health and Development, London, United Kingdom
}

Promoting student collaboration has often been viewed as one of the many challenges instructors face in the educational setting. Collaboration conjures up notions of students who resist working in groups, students who struggle in creating equitable team effort and the difficulty of evaluating and ultimately grading the productivity produced by students and student groups [1]. Collaborative learning is certainly not a novel teaching strategy with research dating back to the 1970s [2]. In the online environment, student collaboration has come in the form of a computer-mediated version of its in-class traditional counterpart. It has come in forms of discussion boards, blogs, and wikis, the intention of which is to ultimately promote critical thinking and creativity.

Despite its rather attractive and novel appeal in using computermediated communication software, online collaboration has posed a challenge to instructors and issues on how to deploy emerging computational technologies that could fully support online collaborative learning, teaching activities, and enhance the overall learning experience [3]. A misconception of online collaborative learning regards instructors who assume collaborative learning strategies that were shown to be successful in traditional in-class courses could fit into online courses with little to no adjustment. Some educators assumed that the exposure to technology-driven collaborative environment would automatically initiate and lead to student collaboration [3].

What may be even more shrouded with ambiguity are the foundational theories and frameworks involved in online collaborative learning. Some authors Reeves, et al. [4] and Tsai [5] have indicated the existence of gaps between the theoretical ideal and the practical application of online collaborative approaches. Tu [6] suggested that some theoretical constructs found in online collaborative learning are also found in aspects of cooperative learning.

One of these constructs is the importance of interactivity and active learning. Collaboration will not occur unless students are given authority over their learning activities. Online collaborative learning engages students in knowledge sharing, inspiration, dependence on one another, and the applications of social interactions within a small group [6]. Another construct is the importance of empowering the learner. Educators must be able to empower online students with the determination and accountability of how, what, and when to learn. Instead of forcing students into identical learning patterns, the educator takes on the role of facilitator to guide the learning experience while incorporating various elements and characteristics that accommodate diverse learning styles. Another construct of online collaborative learning is the idea of the 'community.' Collaboration makes the assumption that knowledge is socially constructed. Students should be able to associate what they have and will learn with a sense of connection that fosters the social context and community dynamics [6].
The trends of pedagogy in higher education have begun to merge with the emergence of computer-mediated and web-based technology that allows and enhances greater student learning control, responsibility, student collaboration. This has become obvious in several countries, including the United States, where college students are required to take at least one introductory computer course for the purpose of improving computer literacy and computing skills [7]. According to Roberts [8], this convergence was brought about due to the attractive appearance that the e-learning setting has given to self-directed learners who seek meaningful and engaging activities, as well as interested educators who are willing to dabble with various technological techniques, practices, and approaches to facilitate the collaborative learning experience.

Faced with the growing challenges of developing instruction for technology-driven education, some educators find difficulty in making the connection between pedagogy and technology [8]. Either educators may be unfamiliar with the technology or they may simply be oblivious in translating formal in-class education into the e-learning setting. It is because of this unfamiliarity, given the crucial nature of these important skills, that online pedagogy is a key feature of many online instructor-training programs [8].

Some of the technologies that support the online collaborative learning atmosphere include the wiki, the podcast, and the discussion forum. Stemming from the Hawaiian word wiki-wiki, meaning 'fast,' a wiki is a web-based tool that has the capability of being edited and has the capacity to link one webpage to another. Some view the wiki as among the most influential tools in online collaborative learning [9]. Podcasting is defined as a series of downloadable published digital files such as audio, video, or other portable digital media distributed online using portable devices such as smart phones, iPods, or computers [10]. Finally, the discussion forum is a form of online collaborative communication where users that are not co-located can asynchronously communicate conveniently through a designated and facilitated forum. However, this form of collaborative communication can seem slow, with users waiting hours or days until they receive a response to a posted message [11]. These examples of online learning only serve to indicate that teaching is no longer limited to the traditional walk, talk, and chalk.

Online collaborative learning has become increasingly important

Correspondence to: Basil H. Aboul-Enein, London School of Hygiene and Tropical Medicine, Department of Global Health and Development, London, United Kingdom, E-mail: Basil.Aboul-Enein@lshtm.ac.uk

Received: December 14, 2016; Accepted: January 02, 2017; Published: January 05,2017 
since online enrollments have increased substantially more than oncampus enrollment [12]. Johnson and Johnson [13] stated that our current society has moved to such lengths that the ability for students to work collaboratively and coordinate their efforts has become more and more crucial to the advancement of knowledge, resulting in greater achievement than individualistic learning and influencing their eventual success in future vocations. Online collaborative learning could serve as a productive tool in the efforts to help students develop the necessary skills in becoming proactive interprofessional team members. These new lengths will only be expanded as new forms of collaborative learning continue to unfold.

\section{References}

1. Palloff RH, Pratt K (2005) Collaborating online: Learning together in community. San Francisco, CA: Jossey-Bass.

2. Reinman P, Spada H (1996) Learning in humans and machines: Towards an interdisciplinary learning science. New York, NY: Pergamon.

3. Zhan H (2008) The effectiveness of instructional models with collaborative learning approaches in undergraduate online courses. (Doctoral dissertation). Northern Arizona University, Flagstaff, AZ

4. Reeves TC, Herrington J, Oliver R (2004) A development research agenda for online collaborative learning. Educational Technology Research and Development 52: 53-65.

5. Tsai CW (2010) Do students need teacher's initiation in online collaborative learning?
Computers \& Education 54: 1137-1144.

6. Tu CH (2004) Online collaborative learning communities: Twenty-one designs to building an online collaborative learning community. Westport, CT: Libraries Unlimited.

7. Sun PC, Tsai RJ, Finger G, Chen YY, Yeh D (2008) What drives a successful e-learning? An empirical investigation of the critical factors influencing learner satisfaction Computers and Education 50: 1183-1202.

8. Roberts TS (2004) Online collaborative learning: Theory and practice. Hershey, PA Information Science Publishing.

9. Wever BD, Keer HV, Schellens T, Valcke M (2011) Assessing collaboration in a wiki: The reliability of university students' peer assessment. Internet and Higher Education 14: 201-206.

10. Bartle E, Longnecker N, Pegrum M (2011) Collaboration, contextualisation and communication using new media: Introducing podcasting into an undergraduate chemistry class. International Journal of Innovation in Science and Mathematics Education 19: 16-28.

11. Ioannou A, Artino Jr AR (2009) Wiki and threaded discussion for online collaborative activities: Students' perceptions and use. Journal of Emerging Technologies in Web Intelligence 1: 97-106.

12. Ku HY, Tseng HW, Akarasriworn C (2013) Collaboration factors, teamwork satisfaction, and student attitudes toward online collaborative learning. Computers in Human Behavior 29: 922-929.

13. Johnson DW, Johnson FP (2003) Joining together: Group theory and group skills. Boston, MA: Allyn \& Bacon.

Copyright: $\mathbb{C} 2017$ Aboul-Enein BH. This is an open-access article distributed under the terms of the Creative Commons Attribution License, which permits unrestricted use, distribution, and reproduction in any medium, provided the original author and source are credited. 